\title{
Quantitative characterization and comprehensive evaluation of regional water resources using the Three Red Lines method
}

\author{
ZANG Zheng ${ }^{1},{ }^{*}$ ZOU Xinqing ${ }^{1,2,3}, \mathrm{XI} \mathrm{Xu}^{4}$, ZHANG Yu${ }^{4}$, ZHENG Defeng ${ }^{4}$, \\ SUN Caizhi ${ }^{4}$
}

1. School of Geographic and Oceanographic Sciences, Nanjing University, Nanjing 210023, China;

2. Collaborative Innovation Center of South China Sea Studies, Nanjing 210093, China;

3. Key Laboratory of Coastal and Island Development (Nanjing University), Ministry of Education, Nanjing 210023, China;

4. School of Urban Planning and Environmental Science, Liaoning Normal University, Dalian 116029, Liaoning, China

\begin{abstract}
Based on the synergetic development of new industrialization, rapid urbanization and agricultural modernization (IUAM), and from the viewpoint of interactive relationships between water resources and regional population, eco-environment, economy and society, the concepts of water resources intensity (WRI), water environment intensity (WEI), water resources relative efficiency (WRRE) and water environment relative efficiency (WERE) are defined with reference to energy intensity, resources efficiency and environment efficiency theory. On the basis of benchmarking theory, the quantitative characterization and evaluation method of "Three Red Lines" (the upper limit of water resources allocation, the baseline of utilization efficiency of water resources and the upper limit of sewage discharge) is proposed. According to these concepts and models, an empirical analysis of the Three Red Lines of water resources on the Chinese mainland between 2003 and 2012 was carried out. The results showed that total water consumption in eastern, central and western parts of China possesses "club convergence" characteristics, which means these areas have similar internal conditions appeared convergence in the development. Inter-provincial differences in water consumption continue to decrease, but the north-south differentiation characteristics in the eastern and central regions were still relatively obvious, while provincial differences in the eastern part were at a minimum and the central region had the largest. Water Resources Efficiency (WRE) of all four sectors in the Southwest rivers and Huaihe River basins were generally high. Industrial WRRE in the Songhua River, Yangtze River and Pearl River basins, agricultural WRRE in the Songhua River, Yellow River and northwestern river basins and domestic WRRE in the Liaohe River, Yangtze River and Pearl River basins were all low. Eco-environmental WRRE in the southeastern rivers and Yangtze River basins were low but showed an upward trend. Other river basins, except for the Northwestern rivers basin, had high eco-environmental WRRE with a downward trend. Western China, especially the northwestern part,
\end{abstract}

Received: 2015-07-03 Accepted: 2015-10-22

Foundation: National Basic Science Personnel Training Fund, No.J1103408; National Key Basic Research Program of China (973 program), No.2013CB956503

Author: Zang Zheng (1978-), PhD Candidate, specializes in management of natural resources.

E-mail: zangzheng@126.com

"Corresponding author: Zou Xinqing, Professor, E-mail: zouxq@nju.edu.cn 
had a low relative intensity of the water environment (WERI) and high integrated water environment management (IWEM) performance, but the relative intensities of the water resources (WRRI) were fairly high, and the comprehensive performance of integrated water resources management (IWRM) in these regions was low. In southern China, especially the southeastern part, the IWEM was fairly high, but the overall IWRM was lower.

Keywords: resource sciences; integrated management; empirical analysis; Red Line; China

\section{Introduction}

With the rapid development of the global economy and of society in general, the overall demand for water by humans is increasing. In the context of global climate change, the multi-dimensional interactions between water resources shortage, water ecological degradation, water environmental pollution and regional eco-environmental protection, economic growth and social development at different spatio-temporal scales and levels emphasize the contradiction between the supply of and demand for local water resources and have become the critical factors restricting socioeconomic and development (in the context of global climate change, the mutual coupling of water resources shortage at different spatial-temporal scales, water ecological degradation, water environmental pollution and regional eco-environmental protection, economic growth and social development had become the critical factors which restricted economic and social development). Since the 1990s, the concept of sustainable development has become widely accepted throughout the world. Several western countries proposed that water resources should be managed as part of regional sustainable development through the concept of Integrated Water Resources Management (IWRM). This practice which originated 20 years ago as a guiding theoretical frame for national water affairs has developed into a management approach for regional sustainable development based on unified management of river basins (Shokoohi and Morovati, 2015; Nikolic et al., 2013), has evolved beyond the scope of simple water resources management and has become closely related to the development and utilization of basin natural resources, basin eco-environmental protection and basin socio-economic development (Anzaldia et al., 2014; Ching and Mukherjee, 2015; Hemamalinia et al., 2015).

At present, China is in a critical period of synergistic and interactive industrialization, rapid urbanization and agricultural modernization (IUAM). Rapid changes in urban and rural population, land use types and scales of industrial and agricultural production lead to a conflict between supply and demand of water resources and to water resources pollution, with consequent pressures on regional sustainable development (Wang et al., 2014; Yang and Liu, 2014). Sustainable utilization of water resources in some regions became critical (Ling et al., 2012; Li et al., 2014; Bao and Chen, 2015). In such a changing environment, a resources management scheme known as the Most Stringent Water Resources Management System (MSWRMS) was proposed by Ministry of Water Resources on the foundation of China's basic water situation at the national conference on water conservancy held in 2009 . At the conference, a proposal was put forward to establish a red line system of water resources management, and relevant departments were required to work out the "Three Red Lines", including control of the amount of water resources, control of utilization efficiency of water resources and control of pollutants entering the water environment, to enhance IWRM. From then on, in accordance with No. 1 Document of central government and the 18th CPC Na- 
tional Congress, the MSWRMS and the Three Red Lines were established as the critical guiding ideology of China's water conservancy for the next generation. Because uneven spatial-temporal distribution of water resources and complex relationships between humans and water resources create great difficulties for regional water resources management, some domestic scholars have carried out studies on the ideas underlying the MSWRMS and "Red Line Management of Water Resources". Yang et al. (2012) summarized the concept of IWRM as used in other countries and compared it with the MSWRMS used in China. They concluded that the latter enriched and expanded the former. Huang and Geng (2011) discussed the innovative ideas of various water resources management systems, and then illustrated the general framework of water resources management systems on the basis of the Three Red Lines by referencing the experiences of water resources management in other countries. Chen and Huang (2011) analyzed the regional differences in the Three Red Lines management from the viewpoint of the uneven distribution of water resources in China. They proposed improved measures and approaches to eliminate the weak links in engineering construction and water resources management. Yang et al. (2013) proposed an evaluation index system by using an analytic hierarchic process (AHP) according to the current situation and characteristics of regional water resources management. This index system comprised nine criteria and 27 indicators involving three fields of the Three Red Lines. Tao et al. (2012) presented 27 control indicators based on the target of the MSWRMS and determined reference criteria of the relative indicators according to laws and regulations, market mechanism and the supply-demand conditions of water resources. Guan et al. (2013) established an evaluation system of water resources management consisting of 12 indicators on the basis of management contents of the Three Red Lines and completed grading evaluation by the Optimal Distance method. In addition, Liang and Zuo (2013), Sun and Chen (2011) and Liu et al. (2014) used Human-Water Harmony Theory, Comparative Analysis Method and AHP, respectively, to complete empirical research into the Three Red Lines of water resources management in the cities of Xinmi in Henan Province, Wuhan in Hubei Province and Beijing. They discussed the integrated management plan of water resources according to the local situation viewed from different aspects.

Following a reviewing of the literature, most studies were found to be based on the concept, the management system of the MSWRMS and the Three Red Lines at the macro level. There were far fewer quantitative evaluation studies. Among the latter, uncertainty of the meaning made promoting and applying research results difficult. In addition, the studies of water resources utilization efficiency (WUE) based on a single water sector (utilization efficiency of industrial water, agricultural water or domestic water consumption) were more common, and the isolated evaluation results could not fully support comprehensive decisions.

Against the background of IUAM that China has actively promoted and using the concepts of energy intensity, resources efficiency and environment efficiency as reference points, this paper puts forward the characterization method known as the Three Red Lines (the upper limit of the funding allocation to water resources, the baseline of utilization efficiency on water resources and the upper limit of sewage discharge) from the viewpoint of a compound system composed of regional water resources, the local population, the eco-environment and socioeconomic and development. Taking the water resources of the Chinese mainland as the 
input data, the Three Red Lines of water resources utilization between 2003 and 2012 at different spatial scales were characterized and evaluated using the above-mentioned concepts and models. The results of this empirical analysis provide a reference framework for other countries to implement the Three Red Lines management policy and explore an integrated management plan of regional water resources and water environment according to the Chinese experience.

\section{Concepts and methods}

Energy intensity, i.e. the consumption intensity of energy (Zheng et al., 2014), is one of the key indicators in measuring the relationship between economic development and energy consumption of a country or a region, and is usually characterized by energy consumption per GDP (tce/10,000 CNY). Linking energy and water usage is a challenge to achieving a sustainable future (Hussey and Pittock, 2012; The Royal Society, 2012), water resources consumption per GDP, which resembles to the concept of energy intensity, is an important indicator for measuring the WUE in the production of the gross national product, meaning the amount of water resources that were consumed to produce one unit of GDP. Higher consumption of water resources per GDP indicates higher dependence of the economy on water resources, whereas lower consumption indicates lower dependence.

\subsection{Concept and method of characterization of WRI and WEI}

Water is an important natural resource for production, domestic living and eco-environment (PDE), which constitutes a large, complex PRED system (made up of the population subsystem $\mathrm{P}$, the water resources subsystem $\mathrm{R}$, the eco-environment subsystem $\mathrm{E}$ and the development subsystem D) with regional population, the environment and socio-economic development. In order to more fully reflect the importance of water resources in sustaining human activity, promoting economic development and protecting the eco-environment, this paper defines the concept of intensity of water resources based on the concept of water resources consumption per GDP: water resources consumption for unit scales of PDE. The formula is given by

$$
W R I\left\{\begin{array}{l}
W R I_{1}=W R A_{1} / A_{1} \\
W R I_{2}=W R A_{2} / A_{2} \\
W R I_{3}=W R A_{3} / A_{3}
\end{array}\right.
$$

where $W R A_{1}, W R A_{2}$ and $W R A_{3}$ represent human water consumption in production, living and eco-environmental conservation processes, respectively $\left(\mathrm{m}^{3}\right) . A_{1}, A_{2}$ and $A_{3}$ represent the water support sizes of production, living and the eco-environment, and they can be characterized by the quantity of economic output, population and available ecological occupied land area (10,000 CNY, person, $\left.\mathrm{hm}^{2}\right)$. By analogy, $W R I_{1}, W R I_{2}$ and $W R I_{3}$ represent the WRI of the corresponding water sectors $\left(\mathrm{m}^{3} / 10,000 \mathrm{CNY}, \mathrm{m}^{3} /\right.$ person and $\left.\mathrm{m}^{3} \mathrm{hm}^{-2}\right)$. The greater its value, the more consumption of PDE there is, and vice versa. Due to the differences in the process of water consumption, WRI can be further subdivided into industrial water consumption intensity, agricultural water consumption intensity and services water consumption intensity, urban residents living water consumption intensity and rural residents living water consumption intensity, natural ecosystem water consumption intensity, artificial ecosystem 
water consumption intensity and natural-artificial ecosystem water consumption intensity (limited by data constraints, industrial and agricultural consumption water, domestic consumption water, urban green space consumption water represented to case study in the following article).

Under the conditions of a specific period and a certain productivity level, natural resources utilization includes not only the low-entropy materials' consumption (such as water, plants and mineral resources) but also the production of high-entropy waste products (such as exhaust gases, waste water and solid waste). Therefore, the demand by humans of PDE water includes both quantity and quality. Only water meeting a certain quality standard can satisfy the normal demands of PDE. Based on the pollutant discharge intensity in environmental science, as well as on formula (1) and related concepts, a macro model of water environment intensity (WEI) (based on the sewage discharge of a unit of PDE) is proposed as follows:

$$
W E I\left\{\begin{array}{l}
W E I_{1}=W E A_{1} / A_{1} \\
W E I_{2}=W E A_{2} / A_{2} \\
W E I_{3}=W E A_{3} / A_{3}
\end{array}\right.
$$

where $W E I_{1}, W E I_{2}$ and $W E I_{3}$, respectively, stand for the pollution intensity of the water environment of the corresponding sectors (i.e. WEI, $\mathrm{m}^{3} 10,000 \mathrm{CNY}, \mathrm{m}^{3} /$ person or $\mathrm{m}^{3} \mathrm{hm}^{-2}$ ). $W E A_{1}, W E A_{2}$ and $W E A_{3}$ represent the quantity of sewage produced in the process of obtaining and utilizing PDE water by humans and that cannot be normally or directly utilized $\left(\mathrm{m}^{3}\right)$. A larger value of WEI shows the greater quantity of sewage accompanying PDE water per unit scale, and vice versa (limited by data constraints, we shall analyze the WEI model in the following case study from the perspective of industrial water and domestic water usage on the Chinese mainland).

\subsection{Method of characterization of WRRI and WERI}

According to the definition and characterization given above, WRI and WEI are both characterization values of resources efficiency and environment efficiency. For a particular area or period, they are closely related to human productivity levels, customs in daily life, eco-environmental conditions and the distribution of regional water resources. Thus WRI and WEI are dynamic concepts that include the connotation of a relative limit (Long et al., 2004).

Benchmarking Management is a modern enterprise administration technique. As an important instrument to assess organizational performance, and to promote management reform, the Benchmarking Management concept has recently spread to public service management to enable the criteria of performance assessment to be determined (Lai et al., 2011; Tsagarakis, 2013). For easy comparison, relative intensity of the water resources (WRRI) and relative intensity of the water environment (WERI) models were put forward by referencing Benchmarking Management theory:

$$
W R R I\left\{\begin{array}{l}
W R R I_{1}=W R I_{1} / \mathrm{S}_{\mathrm{C} 1} \\
W R R I_{2}=W R I_{2} / \mathrm{S}_{\mathrm{C} 2} \\
W R R I_{3}=W R I_{3} / \mathrm{S}_{\mathrm{C} 3}
\end{array}\right.
$$




$$
W E R I\left\{\begin{array}{l}
W E R I_{1}=W E I_{1} / \mathrm{S}_{\mathrm{P} 1} \\
W E R I_{2}=W E I_{2} / \mathrm{S}_{\mathrm{P} 2} \\
W E R I_{3}=W E I_{3} / \mathrm{S}_{\mathrm{P} 3}
\end{array}\right.
$$

where $\mathrm{S}_{\mathrm{C} 1}-\mathrm{S}_{\mathrm{C} 3}$ represent the benchmark values of optimal WRI (the upper limit) for some water sector in a certain period. $W R R I_{1}-W R R I_{3}$ are the relative intensities of regional water resources (WRRI, zero dimension). WRRI $=1$ means that the WRI of the research region was in the pole position; WRRI $<1$ means the WRI was better than the benchmarking value (the smaller the better), and vice versa. In the same way, the $W E R I$ was characterized by formula (4): WERI denotes the relative distance between the real WERI and the upper limit $\left(\mathrm{S}_{\mathrm{P} 1}-\mathrm{S}_{\mathrm{P} 3}\right)$. A large value of $W E R I$ means a higher sewage discharge intensity of the region being evaluated; $W E R I=1$ indicates that it is a relative benchmark position.

Resources efficiency and environmental efficiency are the indicators used to measure the relationship between input and output. According to the definitions of WRI and WEI above, it is obvious that WRI and WRE are inversely related, as are WEI and Water Environment Efficiency (WEE). Thus, water resources consumption and water environmental pollutant production is the input (cost) of survival and development, and the PDE scale supported by them is the output. Therefore, relative efficiency models are proposed as follows, according to the relationship between WRRI and WERI:

$$
\begin{aligned}
& W R R E\left\{\begin{array}{l}
W R R E_{1}=1 / W R R I_{1} \\
W R R E_{2}=1 / W R R I_{2} \\
W R R E_{3}=1 / W R R I_{3}
\end{array}\right. \\
& \text { WERE }\left\{\begin{array}{l}
W E R E_{1}=1 / W R E I_{1} \\
W E R E_{2}=1 / W R E I_{2} \\
W E R E_{3}=1 / W R E I_{3}
\end{array}\right.
\end{aligned}
$$

where WRRE and WERE are, respectively, the relative efficiency of water resources and the relative efficiency of the water environment (subscripts 1-3 in WRRE and WERE correspond to the sectors and are dimensionless). WRRE or WERE $>1$ denotes the WRRI or WERI of the research area is above the reference standard (Benchmarking). That is to say, large values of WRRE or WERE mean high water resources relative efficiency or water environment relative efficiency, while $W R R E$ or $W E R E<1$ mean low water resources relative efficiency or water environment relative efficiency.

\subsection{Characterization and evaluation of Three Red Lines model on water resources}

According to the concepts and characterization methods discussed above, combining the management target of the Three Red Lines proposed at the National Water Resources Conference in 2009 and the fuzzy recognition models I-III (Table 1), the measuring standard to carry out Three Red Lines on IWRM is given in Table 1 (total control red line is indicated by the ratio between actual consumption of the evaluated area's water sector $\left(W R A_{1}-W R A_{3}\right)$ and its benchmark value; it was found that the value of the conversion by the formula is equal to $W R R I_{1}-W R R I_{3}$, which is model I). 
Table 1 Recognition and measuring standard of the Three Red Lines on IWRM and IWEM

\begin{tabular}{|c|c|c|c|}
\hline $\begin{array}{c}\text { Serial } \\
\text { number }\end{array}$ & Model & $\begin{array}{l}\text { Control } \\
\text { objective }\end{array}$ & Measuring standard \\
\hline I & $\begin{array}{l}W R R I_{1}=? \\
W R R I_{2}=? \\
W R R I_{3}=?\end{array}$ & WRA & $\begin{array}{l}W R R I_{1}-W R R I_{3}=1 \text { means consumption amount of water resources in the study area } \\
\text { is exactly on the upper limit (red line) while } W R R I_{1}-W R R I_{3}<1 \text { or } W R R I_{1}-W R R I_{3}>1 \\
\text { is under or over the red line of amount control. }\end{array}$ \\
\hline II & $\begin{array}{l}W R R E_{1}=? \\
W R R E_{2}=? \\
W R R E_{3}=?\end{array}$ & WRE & $\begin{array}{l}W R R E_{1}-W R R E_{3}=1 \text { means WUE in the study area is exactly on the upper limit (red } \\
\text { line) while } W R R E_{1}-W R R E_{3}<1 \text { or } W R R E_{1}-W R R E_{3}>1 \text { under or over the red line of } \\
\text { efficiency control. }\end{array}$ \\
\hline III & $\begin{array}{l}W E R E_{1}=? \\
W E R E_{2}=? \\
W E R E_{3}=?\end{array}$ & WEE & $\begin{array}{l}W E R E_{1}-W E R E_{3}=1 \text { means water environment relative efficiency in the study re- } \\
\text { search area is exactly on the upper limit (red line) while } W E R E_{1}-W E R E_{3}<1 \text { or } \\
W E R E_{1}-W E R E_{3}>1 \text { under or over the red line of water environment relative effi- } \\
\text { ciency. }\end{array}$ \\
\hline
\end{tabular}

As mentioned above, water resources and other elements that are coupled constitute a water resources system with $n$ subsystems. Similarly, water environment and other elements that are coupled constitute a water environment system. With respect to PDE scales supported by water resources and water environment elements, they were divided into three subsystems (i.e. the water resources/environment-population subsystem, the water resources/environment-eco-environment subsystem and the water resources/environment-production subsystem). Each subsystem is formed of $m$ elements. As mentioned above, the water resources/environment-population subsystem includes both urban and rural population, the water resources/environment-eco-environment subsystem includes the natural environment, the artificial environment and the artificial-natural environment, and the water resources/environment-production subsystem includes the agricultural, industrial and service production. To measure the performance of regional IWRM and IWEM, two measurement indicators are proposed using the comprehensive evaluation method:

$$
\begin{aligned}
& I W R M=\sum_{i=1}^{n} \sum_{j=1}^{m}\left(w_{i j} \cdot W R R E_{i j}\right) \\
& I W E M=\sum_{i=1}^{n} \sum_{j=1}^{m}\left(w_{i j} \cdot W E R E_{i j}\right)
\end{aligned}
$$

where $I W R M$ and IWEM stand for the integrated water resources management performance index and the water environment management performance index, respectively; $i$ and $j$ represent each subsystem's water sector of the PRED system; $w_{i j}$ is the normalized weight of each subsystem and each water sector. Therefore, the value of comprehensive performance ranges between 0 and 1 and is divided into four grades by the Delphi method. IWRM or $I W E M \in(0,0.25]$ means low performance, $I W R M$ or $I W E M \in(0.25,0.5]$ means relatively low performance, $I W R M$ or $\operatorname{IWEM} \in(0.5,0.75]$ means relatively high performance and $I W R M$ or $I W E M \in(0.75,1.0)$ means high performance.

\section{Empirical analysis}

To fully reflect the utilization of water resources in different areas or basins, taking into account data availability, we evaluated the temporal evolution and spatial distribution of water resources using the Three Red Lines management policy on the Chinese mainland (Figure 1. Hong Kong, Macao, Taiwan and the South China Sea Islands were not included) between 2003 and 2012, taking the Chinese mainland average value of the investigation period as a 
relative optimum reference standard and benchmark (Table 2). The data for PDE water consumption came from the Water Resources Bulletin (limited data: production water included only industrial and agricultural water, water for living purposed did not distinguish between urban and rural, ecological and environmental water were temporarily represented by the artificial ecosystem water, and each weighting factor of these four water sectors was taken as 0.25$)$.

(a) East-west partition

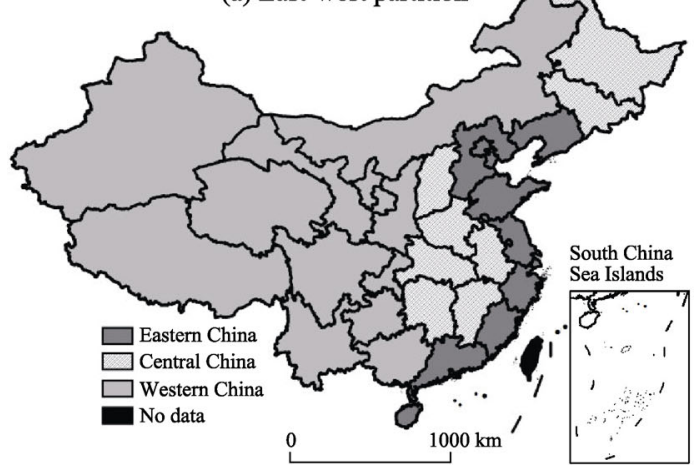

(b) North-south partition

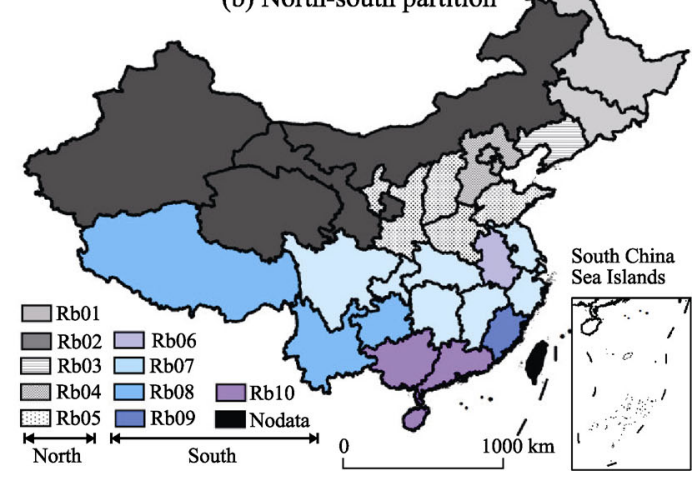

Note: Eastern China includes Liaoning, Hebei, Beijing, Tianjin, Shandong, Jiangsu, Shanghai, Zhejiang, Fujian, Guangdong and Hainan Provinces; Central China consists of Heilongjiang, Jilin, Shanxi, Henan, Anhui, Hubei, Hunan and Jiangxi Provinces; Western China includes Inner Mongolia, Gansu, Ningxia, Shaanxi, Xinjiang, Qinghai, Tibet, Sichuan, Chongqing, Guizhou, Yunnan and Guangxi provincial units. Rb01-10 represent Songhua River basin, northwestern river basins, Liaohe River basin, Haihe River basin, Yellow River basin, Huaihe River basin, Yangtze River basin, Southwestern basin rivers, southeastern river basins and Pearl River basin, respectively.

Figure 1 Diagram of administrative division at provincial level and compartment of first-grade region of water resources on the Chinese mainland

Table 2 Benchmarking of Chinese mainland integrated management target of water resources and water environment

\begin{tabular}{|c|c|c|c|c|c|c|c|c|c|c|}
\hline \multicolumn{2}{|c|}{ Year } & 2003 & 2004 & 2005 & 2006 & 2007 & 2008 & 2009 & 2010 & 2011 \\
\hline \multicolumn{2}{|c|}{$\mathrm{A}\left(\mathrm{A}_{1}+\mathrm{A}_{2}+\mathrm{A}_{3}\right)$} & 5322.7 & 5547.5 & 5633.0 & 5795.0 & 5818.7 & 5910.0 & 5965.1 & 6021.9 & 6106.9 \\
\hline \multirow{4}{*}{$\mathrm{S}_{\mathrm{C}}$} & $\mathrm{S}_{\mathrm{C} 11}$ & 207.3 & 173.5 & 150.5 & 131.0 & 113.8 & 93.8 & 88.3 & 74.9 & 63.0 \\
\hline & $\mathrm{S}_{\mathrm{C} 12}$ & 1998.7 & 1715.8 & 1556.3 & 1481.2 & 1260.2 & 1085.6 & 1056.8 & 910.1 & 788.9 \\
\hline & $\mathrm{S}_{\mathrm{C} 2}$ & 48.8 & 50.1 & 51.6 & 52.8 & 53.8 & 54.9 & 56.1 & 57.1 & 58.6 \\
\hline & $\mathrm{S}_{\mathrm{C} 3}$ & 6728.3 & 6196.5 & 6313.0 & 7039.3 & 6186.6 & 6876.1 & 5165.8 & 5611.4 & 4993.6 \\
\hline \multirow{2}{*}{$\mathrm{S}_{\mathrm{P}}$} & $\mathrm{S}_{\mathrm{P} 1}$ & 37.4 & 31.2 & 28.5 & 23.4 & 20.0 & 16.2 & 14.9 & 12.3 & 11.3 \\
\hline & $\mathrm{S}_{\mathrm{P} 2}$ & 19.3 & 20.2 & 21.9 & 22.9 & 23.8 & 25.1 & 26.8 & 28.5 & 29.8 \\
\hline
\end{tabular}

Note: A means total water consumption (100 million tons); $\mathrm{S}_{\mathrm{C} 11}$ (ton/10,000 CNY); $\mathrm{S}_{\mathrm{C} 12}$ (ton/10,000 CNY); $\mathrm{S}_{\mathrm{C} 2}$ (ton/person); $\mathrm{S}_{\mathrm{C} 3}$ (ton/ha); $\mathrm{S}_{\mathrm{P} 1}$ (ton/10,000 CNY); $\mathrm{S}_{\mathrm{P} 2}$ (ton/person).

Considering the differences in water consumption between different industries, the quantities of industrial and agricultural water used in the production process were evaluated independently. With reference to the statistical data of the Water Resources Bulletin of China (Ministry of Water Resources of China, 2004-2013), eco-environmental water included only artificial supply to the environmental water of towns, as well as the recharge water of several rivers, lakes and wetlands, without including Yangtze water for supplying the Taihu River, environmental water in Zhejiang Province and recharge water for the Daxihaizi Tarim River in Xinjiang, the Tarim River and the Altay area. In addition, the data for economic 
output (industrial and agricultural production) of each research unit, the population at end of the year and the public green land area of each city were obtained from the China Statistical Yearbook (NBSC, 2004-2013a) and the China City Statistical Yearbook (NBSC, 2004-2013b). The statistical data for each first-grade region of water resources were analyzed and calculated by referencing data on the National Guide Rule of Water Resources Division and the Water Resources Bulletin for several basins. Some missing data were calculated by linear interpolation.

\subsection{Analysis of trend in temporal evolution of quantity of water resources and relative utilization efficiency on Chinese mainland}

\subsubsection{Analysis of trend of temporal evolution of total quantity of water resources}

Setting the target for the control of the quantity of water in each province as the benchmark (control benchmarking of each province over each year was determined by the proportion of total provincial allocation in 2015 proposed in Notification on Implementing the Assessment Method of the Most Stringent Water Resources Management System published by the General Office of the State Council as the basis for referring to total water supply on the Chinese mainland), the standard rates for the quantity of water resources for the 31 provinces between 2003 and 2011 and their standard deviations were calculated according to the models in Table 1 and related data, as shown in Figures 2 and 3.

As mentioned already, we separated the total control target of the Chinese mainland provinces and autonomous regions according to their proportion of the total amount of water used on the Chinese mainland in the same period. Combined with the total consumption of water resources for each province, the relative distance to the total control red line can be decided (i.e. water resources relative intensity values, Figure 2). The results indicated that total water consumption on the Chinese mainland is convergent on the whole and locally difference in research period.

In eastern China, the total quantity of water consumed by Beijing and Tianjin and in Liaoning and Shandong provinces was under the red line. Hebei exceeded the red line a few

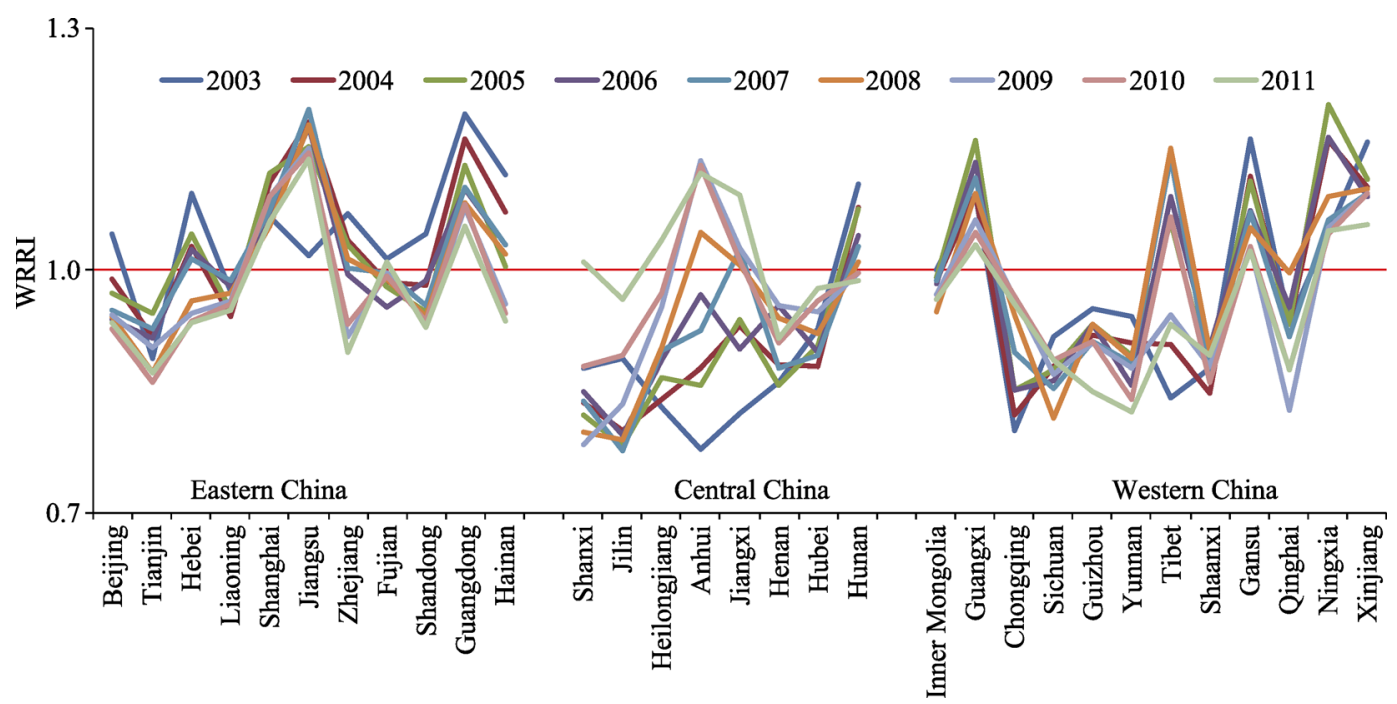

Figure 2 Variation in consumption rate of water resources for provinces on the Chinese mainland 


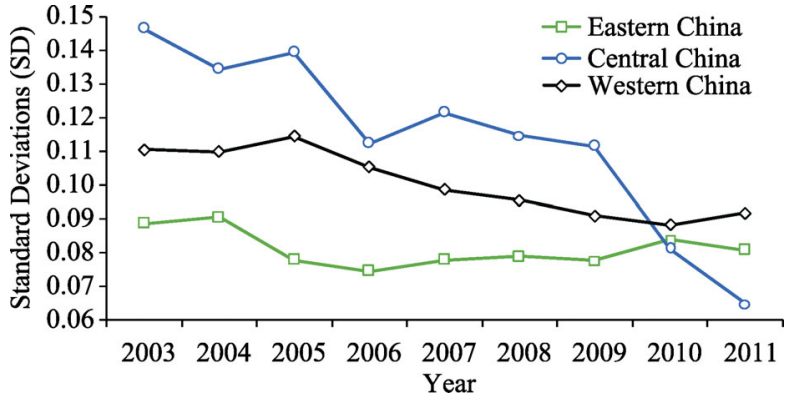

Figure 3 Variation in total water consumption of provinces on the Chinese mainland times, but in recent years its consumption has gradually reduced to below the red line, as there is relatively less availability of water in the northern basin (Figure 1). Over the entire study period, the total quantity of water consumed in Shanghai, Jiangsu and Guangdong provinces was above the red line. We can see therefore that water resources played an important role in the socioeconomic

development of these three provinces. The total amount of consumption water in Zhejiang, Fujian and Hainan provinces were overweight in some years, which may be relative to the situation that water resources are abundant in the southern basin. The standard deviations (Figure 3) reflect the changing trend in the provincial differences. Figure 3 shows that the variation in water consumption in the eastern region during the study period was at first concave and then relatively flat, with values between 2003 and 2010 that were the lowest of the three regions. Although there is an obvious north-south differentiation phenomenon, there are relatively small internal differences between them, and the annual variability of the provincial differences was also low.

In central China, in addition to Hubei Province, the total quantity of water consumed in Anhui, Jiangxi and Hunan provinces located in the southern part of the basin was well above the average in some years, while Shanxi and the other three provinces in the northern basin were largely under the red line. Provincial differences in the central region were higher than those of the eastern and western regions between 2003 and 2009 (Figure 3), which coincides with the internal north-south variation phenomenon. The variations in water consumption data of Figure 3 show that the central region shrank each year except for 2007 and 2008, which were slightly higher than for 2006 .

In western China, the total quantity of water in Inner Mongolia, Chongqing, Sichuan, Guizhou, Yunnan, Shaanxi and Qinghai provinces, which all contain northern basin and southern basin provinces, was under the red line. Guangxi, Gansu, Ningxia and Xinjiang provinces were above the red line in all years. The total water consumption of Tibet crossed the red line after 2008, but the north-south variation phenomenon is not particularly noteworthy. These results suggest that the usability of water resources in the western region may be made more complex by the coupling effect of water resources endowment and socioeconomic development. The variation in provincial consumption of the western region was between that of the eastern and central regions, while the overall trend is downward in all three regions, showing that total water consumption in China has "club convergence" features, which means these areas had similar internal conditions and appeared convergence in the development of total water consumption (Sun et al., 2014).

\subsubsection{Analysis of the temporal evolution trend of WRRE}

The WRRE on PDE water of ten first-grade regions on the Chinese mainland between 2003 and 2011 were calculated according to model II in Table 1, and the results are shown in Figure 3.

Figure 4 shows that the WRRE in the Huaihe River and the southwestern river basins 

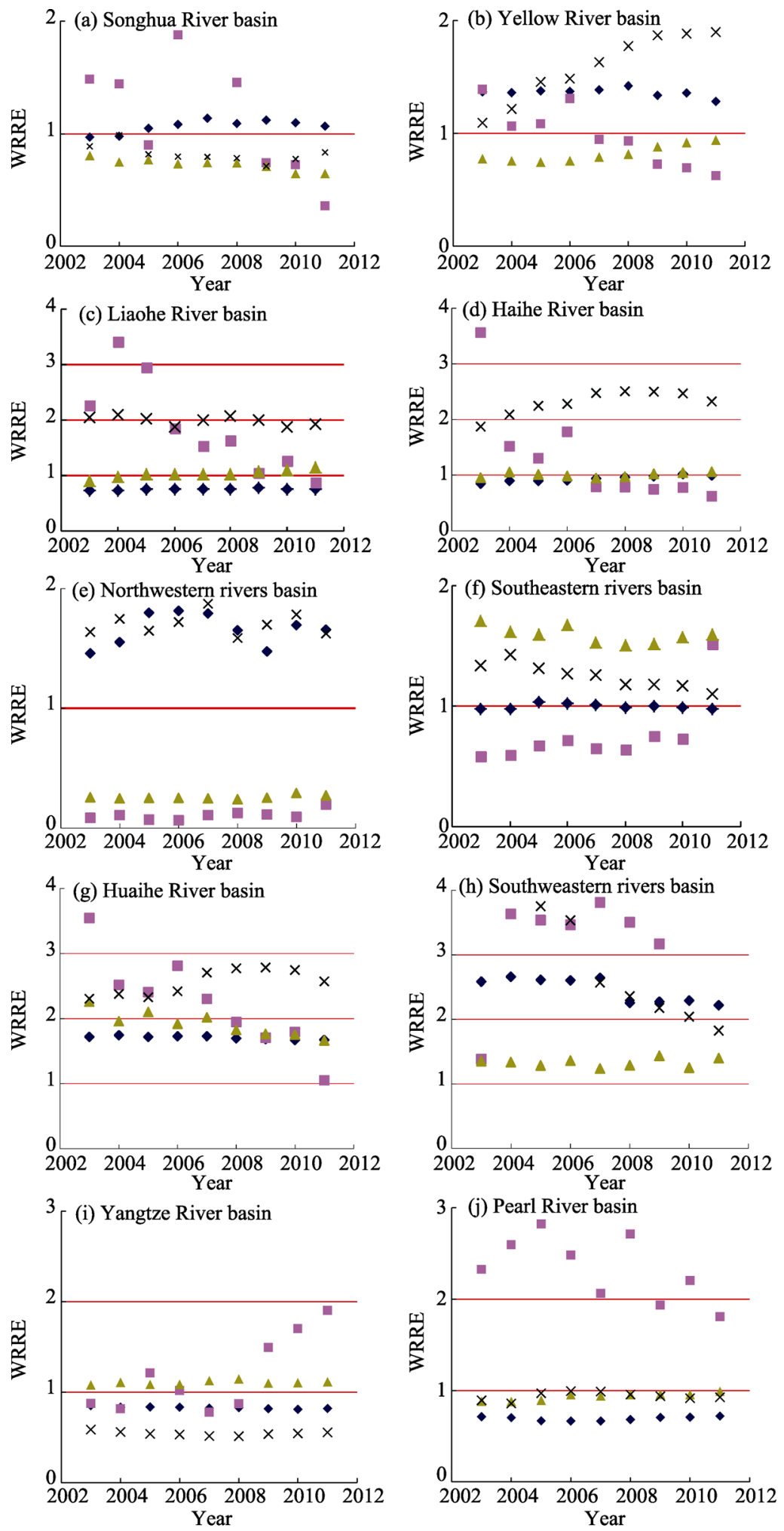

$\downarrow$ Domestic water $\backsim$ Eco-environmental water $\triangle$ Agricultural water $\times$ Industrial water

Figure 4 Variation of WRRE in all first-grade water resource regions on the Chinese mainland 
were relatively high (above the red line in all years), while the WRRE of related water sectors in the other eight basins were below the water resource red line to some degree during the study period.

Between 2003 and 2011, the WRRE in the basins of the Songhua River, the Yangtze River and the Pearl River were below the red line, which was related to the high proportion of older and heavy industries in the Songhua River basin and to abundant water resources in the Yangtze River and Pearl River basins. Thus, the industrial WRRI of these three basins was high and WRRE was low. The industrial WRRI in the river basins of southeast and southwest was high but maintained an upward trend during the study period. In contrast, the industrial WRRI in the other four regions of the north (Liaohe River, Yellow River, Haihe River and the northwestern rivers) exceeded the red line, which indicated that the industrial development mode is good for promoting industrial WUE in these regions with the continual optimization of industrial distribution (Lu et al., 2014).

The agricultural WRRE of the Songhua River, Yellow River and northwestern rivers were under the red line, particularly the agricultural WRRE in the northwestern river basins which was always abnormally low and closely related to the agricultural planting structure, climate and land resources, and other factors (Li et al., 2014). Thus, the relevant local government departments should use the water demand and water consumption characteristics of main grain crops to establish planting systems with efficient utilization of water resources in these regions ( $\mathrm{Li}$ and Huang, 2010). The Songhua River basin is one of the most important commodity grain bases in China. Although it does not lack for sufficient water resources, their uneven distribution, decreasing from east to west and from north to south, led to a low agricultural WRRE.

In summary, the agricultural WRRE in other regions were close to or above the red line. However, considering the fundamental status of agriculture in China, and to ensure food security, it would be difficult to improve the efficiency of agricultural use of water, which is gradually increasing.

For the WRRE of residents' domestic water use, the WRRE of the Liaohe, Yangtze and Pearl River basins were below the red line. Large city belts, such as the central and southern Liaoning, Beijing-Tianjin-Hebei, Yangtze River Delta and Pearl River Delta economic belts, are located in these basins. The Yellow River, Huaihe River, northwestern and southwestern river basins, which have large areas of agricultural population, had high domestic WRRE. Domestic water consumption per capita in these regions was lower than the national average, which was closely related to the eating and living habits of the local residents and to the natural abundance and regional allocation of water resources. The WRRE were always close to the red line in the Haihe River and Southeast rivers basins where the WRRE of residents' domestic water usage were close to the national average.

As for the WRRE of eco-environmental water, during the research period the WRRE in the Huaihe River, Pearl River and southwestern river basins were above the red line. In the other four northern regions except for the northwestern river basins (Figure 1), the WRRE were high at the beginning but then showed a significant downward trend toward the baseline in recent years. The WRRE of the southeastern and Yangtze river basins were low in some years but have shown an upward trend recently. The WRRE in the northwestern river basins have been below the red line over the years as the condition of agricultural water re- 
sources consumption. Eco-environmental water resources in eco-fragile areas need to be improved urgently, but an impracticable goal of full eco-environmental protection would make reasonable utilization of regional water resources more complicated ( $\mathrm{Lu}, 2009)$. Therefore, in the Northwestern inland regions with relatively scarce water resources, ecological planning should be scientifically determined by acknowledging regional realities, and urban public green spaces should be developed by adjusting measures to local conditions.

\subsection{Analysis of spatial distribution of WRRE and WERE on the Chinese mainland}

\subsubsection{Analysis of spatial distribution features of WRRE and WERE}

Using models II and III and relevant data, the WRRE and WERE of each water sector for each of the provinces in 2012 were calculated, and their spatial distribution is shown in Figures 5 and 6.
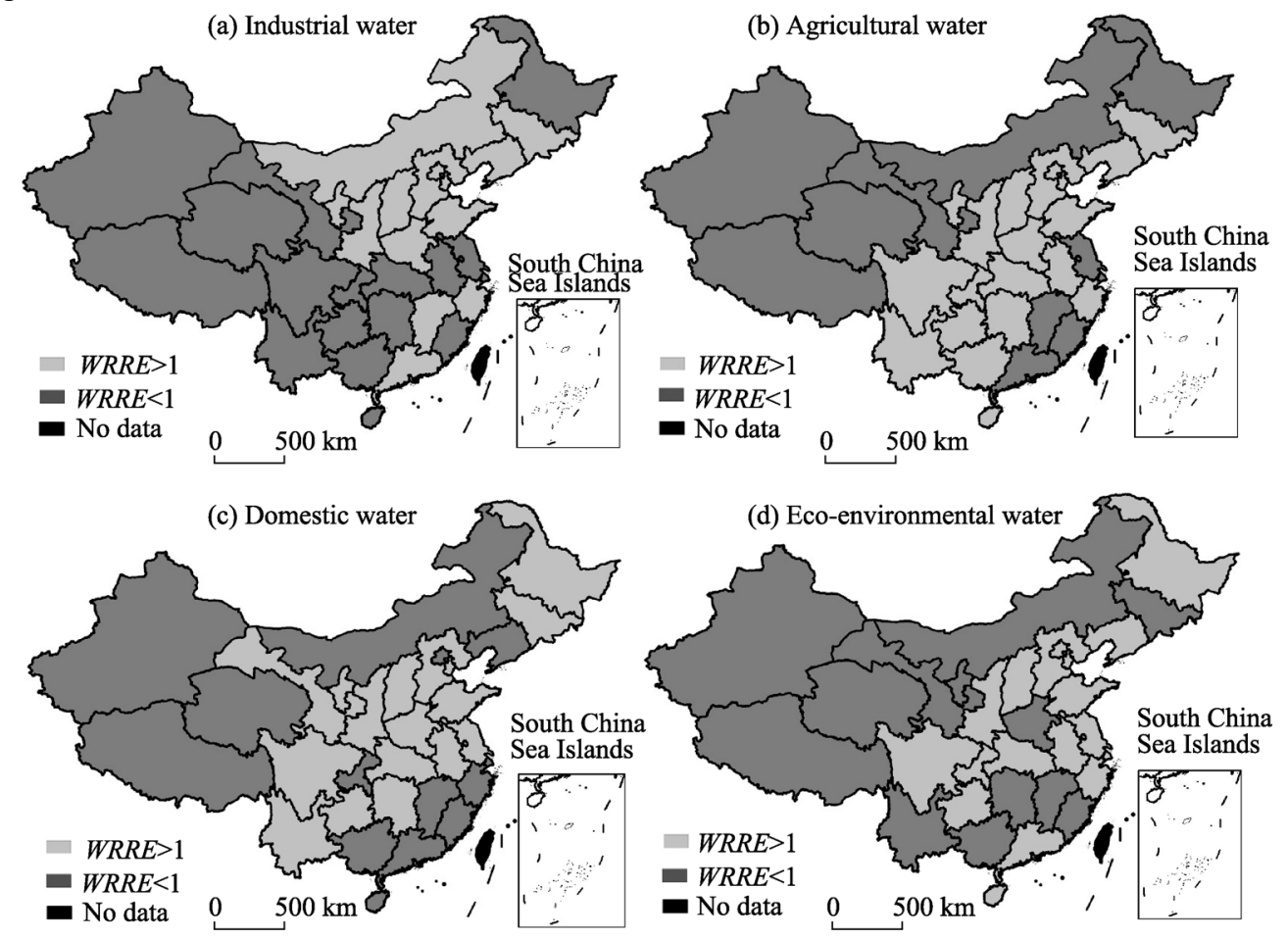

Figure 5 Spatial distribution of WRRE in each province on the Chinese mainland

From an analysis of the WRRE of different water sectors, Figure 5a shows that the industrial WRRE of 17 provinces on the Chinese mainland were below the red line in 2012. Except for Jiangsu, Shanghai, Fujian and Hainan provinces located in eastern China, the other 13 provinces are located in central and western China. From a north-south perspective, except for Zhejiang, Jiangxi and Guangdong provinces, the other 11 provinces having high industrial WRRE are located in the north, which is lacking in water resources. With the industrial WUE of these provinces tending to be stable (Lu et al., 2014), it will be crucial to continually promote new industrialization and the improved industrial WUE can reduce water consumption of industrial added value per 10,000 CNY in the northwestern, southwestern and south central regions in the future. Eleven of the provinces had agricultural WRRE 
that were below the red line. Among them, Jiangsu, Shanghai, Fujian and Guangdong provinces are located in eastern China, while the other seven provinces are located in central and western China (Figure 5b). The WRRE of domestic water consumption showed a distribution with high values in the center and low values in the southeast and northwest regions. There were 17 provinces above the red line while 14 provinces below the red line (Figure 5c). Low WRRE on eco-environmental water consumption had the same distribution as that of agricultural water, mainly located in central and western China. There were 18 provinces with pros and 13 provinces with cons (Figure 5d).

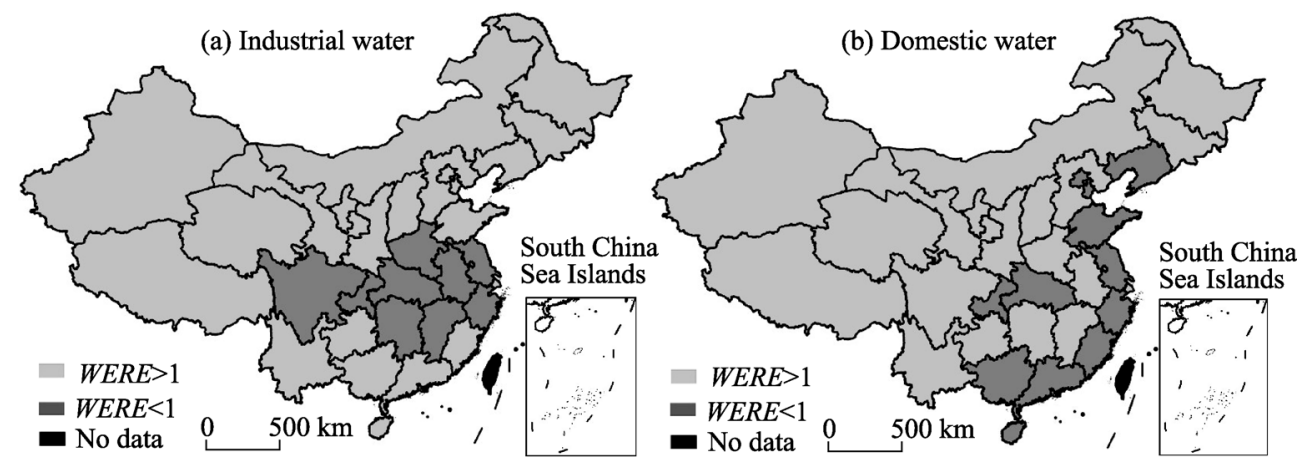

Figure 6 Spatial distribution of WERE in each province on the Chinese mainland

Figure 5 shows that in central and western China, especially in the western provinces that are short of water, the WRREs are generally low. On WERI, the midwest fares better than the east, and there were nine provinces with industrial WERI above the red line $(W E R E<1)$ in 2012. These were clustered in the Yangtze and Huaihe river basins, and their regional industrial WEE were low $(W E R I>1)$. On domestic water, there were 12 provinces that had high WERI. Except for Hebei and Shanghai provinces, nine of the 11 coastal provinces belong to this category. Their WERE on domestic water consumption were low, but the situation in the eastern region does not look favorable for the future (Figure 6b). A dense population and a high urbanization rate in these regions (Beijing, Chongqing and Hubei included) create great difficulties and uncertainties for improving environmental water quality (Huang et al., 2015).

3.2.2 Analysis of spatial distribution features of WRRE and WERE integrated management performance

To illustrate the spatial distribution of WRRE and WERE on the Chinese mainland, the IWRM and IWEM of PDE water in 2012 were obtained from equations (7) and (8) and related data and are shown in Figure 7.

Figure 7 a shows that low IWRMs $(I W R M \leqslant 0.5)$ were found for Xinjiang, Qinghai, Tibet, Inner Mongolia, Heilongjiang, Jiangxi and Guangxi provinces. Except for Heilongjiang and Jiangxi provinces, the other seven provinces are located in western China, where there is a shortage of water resources and economic development has fallen behind. Although these regions had low WERI (Figure 6), considering the general state of sustainable utilization of water resources in China, these provinces should follow the principle of water resources utilization that employs comprehensive planning, regional balance and deployment enhancement $(\mathrm{Lu}, 2011)$ and establishes authoritative organization of unity management on 
basin water resources to strengthen demand and supply coordination of regional water resources. From Figure 6b, we can see that compared with central and western China and the north, the IWEM of 20 provinces located in the eastern coastal areas and the south was low $(I W E M \leqslant 0.5)$. The distribution area was the same as that which had low WERE $(W E R E<1)$ in Figures $6 \mathrm{a}$ and $6 \mathrm{~b}$. The spatial distribution of IWRM and IWEM in China is similar to that of some regions in other countries (XNA, 2010a, 2010b). WUE in these regions lacking water resources is low and water environmental pollution in densely populated regions is heavy. Thus, affected provinces should refer to the idea of IWRM in other countries and explore sustainable utilization of regional water resources and coordinated development of PDE.

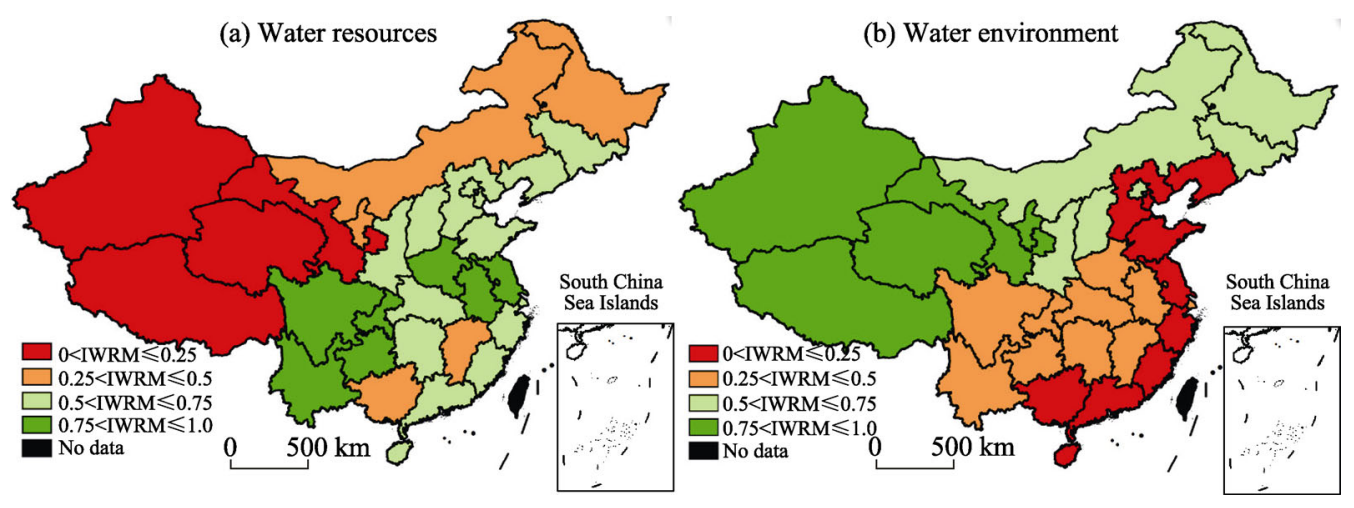

Figure 7 Grade distributions of IWRM and IWEM for the Chinese mainland

The above results indicate that western China, especially the northwestern part, has high WRRI and low WRRE. In the future, with the continuous development of agricultural modernization and rapid urbanization, and under the guidance of macro goals that ensure national food security, improved residents' living standards and advanced ecological civil construction, it will be an important and crucial task to increase regional WUE. On the other hand, preventing the spread of contamination to less developed areas should be made more effective (Miao et al., 2015) and continue to promote regional water environment to a positive cycle. In this regard, the executive meeting of the State Council in May 2014 proposed the construction of 172 important hydraulic projects involved in step-by-step planning from the end of the 12th to the start of the 13th Five-Year Plan (Xiong, 2014) to promote the construction of inter-basin water transfer projects and water-saving irrigation projects in major grain-producing and ecologically vulnerable areas to ensure the water security of important economic regions and the livelihoods of both urban and rural residents. This is a critical moment to improve WUE and ease the conflict between water resources and PDE development in central and western China.

\section{Conclusions and discussion}

With reference to the concepts of energy intensity, resources efficiency and environmental efficiency, we have proposed in this paper the concepts of WRI and WEI that combine the concepts of annual water consumption per 10,000 CNY of industrial added value, annual water consumption per capita, water consumption per hectare of eco-environment, wastewater emissions per 10,000 CNY economic output and the pollution carrying capacity of the 
water environment. On the basis of these concepts, characterization models termed WRRI, WRRE, WERI and WERE have been proposed. Furthermore, the dynamic characterization and evaluation method of the upper limit of quantity allocation to water resources, the baseline of utilization efficiency of water resources and the upper limit of sewage discharge to the water environment were determined. By means of empirical analysis of data on the Chinese mainland during the period 2003 to 2011, we have reached the following preliminary conclusions:

(1) Between 2003 and 2011, the total water consumption on the Chinese mainland is convergent on the whole and locally different in the research period, and the eastern, central and western regions showed obvious "club convergence" features, while inter-provincial differences in the consumption of water continue to decrease. In relative terms, the overall inter-provincial differences in the total water consumption in the central region were the largest and the north-south differentiation appeared the most obvious. Differences between the eastern provinces were minimal, but also showed north-south differentiation characteristics. The western regional variations were between those of the eastern and central regions and displayed complex internal features.

(2) Between 2003 and 2011, the industrial WRE of the Songhua River, Yangtze River and Pearl River basins were low. The agricultural WRE was also low in the Songhua River, Yellow River and northwestern river basins, and the domestic WRE in the Liaohe River, Yangtze River and Pearl River basins were also high. The eco-environmental WRE was low but showed an upward trend in the southeastern and Yangtze river basins, while the eco-environmental WRE in the other four northern regions were high but showed an obvious downward trend. The WRE of all the water sectors in the Southwestern and Huaihe River basins were high.

(3) In 2012, WEI in western China, especially in the northwestern part, was low and the IWEM was high, while WRE and IWRM were both low. However, southern China, especially the southeastern part, showed high IWRM and low IWEM. In the Yangtze and Huaihe River basins, industrial WEI was high. The sewage emissions of the coastal provinces were higher than those of the non-coastal provinces.

Water resources in China are greater in the east than in the west and greater in the south than in the north. Domestic scholars in recent years have proposed numerous ideas to tackle this problem, such as water resources red lining and the establishment and implementation of the MSWRMS. The water resources of all countries and regions are limited, and there are numerous conflicts in the supply and demand of water resources among different regions, different sectors, upstream and downstream of a basin, and human production, living and eco-environment, so that management objectives related to the decomposition of different spatial-temporal scales are still to be solved and require continuous optimization in order to continue to improve this situation. This paper attempts to integrate management and evaluation of regional water resources on the foundation of a baseline (upper limit). Compared with previous research (Yang et al., 2013; Tao et al., 2012; Guan et al., 2013; Liang and Zuo, 2013, Sun and Chen, 2011), this paper proposes an upper limit of quantity allocation to water resources, a baseline of utilization efficiency of water resources and an upper limit on the amount of pollutant entering the water environment into IWRM to propose a dynamic characterization and evaluation plan. Through the strength of this concept, we hope to strengthen peer emphasis on comprehensive evaluation of water resources, and we have accordingly 
proposed the Three Red Lines method of a dynamic water characterization and evaluation model to make up for the deficiencies of qualitative research and to provide data to support relevant research results. On the basis of benchmarking theory, this paper attempts to put forward a water resources and water environment efficiency benchmark, which is both absolute strict and dynamic flexible. The benchmark should be reasonable in theory and necessary in practice so its implementation process can avoid the "one size fits all" problem. Based on this, combining different spatial-temporal scales, time series evolution and spatial patterns, and the quantity and quality of water resources, this paper discusses whether the WRI exceed the red line of water resources and the degree of the excess on the Chinese mainland between 2003 and 2012. The results show that the method is highly demonstrable and operable and can be widely used at different spatial-temporal scales.

It should be pointed out that evaluation and management of water resources involves national or regional politics, socioeconomic development etc., and needs long-term research and practice. As the current efficiency of water use in China and other relevant standards are far from perfect, this paper temporarily takes the mean value of Chinese mainland water resources as the benchmark for the model's empirical analysis, and follow-up work will further investigate and establish the different spatial and temporal scales of water resources and water efficiency benchmarks. Based on integrated management objectives, we have attempted to elaborate the idea that each one of PDE is as important, so that each water department takes equally weight. Other applications may need to consider precedence to protect the status of the water sector and other issues in the spatial-temporal scales, and this can be determined by how flexible the actual situation is. Constrained as we are by data limitations, this article does not propose an all-empirical model: the water required by urban and rural residents for living is combined and not broken down into components, production water does not cover tertiary industrial water, water for the eco-environment is only evaluated for the artificial ecosystem system of water, and so on. More intensive work on these aspects remains to be carried out.

\section{References}

Anzaldia G, Rubiona E, Corcheroa A et al., 2014. Towards an enhanced knowledge-based Decision Support System (DSS) for Integrated Water Resource Management (IWRM). Procedia Engineering, 89: 1097-1104.

Bao C, Chen X J, 2015. The driving effects of urbanization on economic growth and water use change in China: A provincial-level analysis in 1997-2011. Journal of Geographical Sciences, 25(5): 530-544.

Chen J, Huang W, 2011. Explore water resources management issues related to the implementation of "Three Red Lines". China Water Resources, (6): 118-120. (in Chinese)

Ching L, Mukherjee M, 2015. Managing the socio-ecology of very large rivers: Collective choice rules in IWRM narratives. Global Environmental Change, 34: 172-184.

Guan G L, Xu X Y, Xu L, 2013. Study on evaluation system of water resources management according to "Three Red Lines". Yangtze River, 44(7): 64-66. (in Chinese)

Hemamalinia J, Mudgalb B V, Sophiac J D, 2015. Sustainability of tank eco-systems from IWRM perspective. Aquatic Procedia, (4): 633-640.

Huang C C, Zhang M L, Zou J et al., 2015. Changes in land use, climate and the environment during a period of rapid economic development in Jiangsu Province, China. Science of the Total Environment, 536: 173-181.

Huang C S, Geng L H, 2011. Water resources management mode based on "Three Red Lines". China Rural Water and Hydropower, (11): 30-31. (in Chinese)

Hussey K, Pittock J, 2012. The energy-water nexus: Managing the links between energy and water for a sustainable future. Ecology and Society, 17(1): 31. (online) http://dx.doi.org/10.5751/ES-04641-170131.

Lai M C, Huang H C, Wang W K, 2011. Designing a knowledge-based system for benchmarking: A DEA Approach. Knowledge-Based Systems, 24(5): 662-671. 
Li B G, Huang F, 2010. Trends in China's agricultural water use during recent decades using the green and blue water approach. Advances in Water Science, 21(4): 575-583. (in Chinese)

Li Q, Chen H M, Wang Y P, 2014. The interactive effect of agricultural water and agricultural economic growth in Xinjiang. Resources Science, 36(8): 1679-1685. (in Chinese)

Liang S K, Zuo Q T, 2013. Study of water resources allocation based on human-water harmony and "Three Red Lines". Water Resources and Hydropower Engineering, 44(7): 1-4. (in Chinese)

Ling H B, Xu H L, Fu J Y et al., 2012. Surface runoff processes and sustainable utilization of water resources in Manas River Basin, Xinjiang, China. Journal of Arid Land, 4(3): 271-280. (in Chinese)

Liu X, Liu H L, Wang H R et al., 2014 Indicator system and evaluation method of "Three Red Lines" of water resources management in Beijing. Journal of Natural Resources, 29(6): 1017-1028. (in Chinese)

Long T R, Jiang W C, He Q, 2004. Water resources carrying capacity: New perspectives based on eco-economic analysis and sustainable development. Journal of Hydraulic Engineering, (1): 38-45. (in Chinese)

Lu D D, 2009. Deal with economic and social development water use and ecological system water use on perspective of "adjust”. China Water Resources, (19): 26-27. (in Chinese)

Lu D D, 2011. New strategy of western regional development: Enriching people and playing a main functional role should be the core. Resources Environment and Development, (1): 1-2. (in Chinese)

Lu D D, Jia S F, Bai Y P, 2014. Study of the necessity and possibility of water use decrease in northern China. Geographical Research, 33(2): 203-213. (in Chinese)

Miao X, Tang Y, Wong C W, 2015. Environment: Polluters migrate to China's poor areas. Nature, 518, (7540): 483. doi: $10.1038 / 518483$.

National Bureau of Statistics of China (NBSC), 2004-2013. China City Statistical Yearbook: 2003-2012. Beijing: China Statistics Press. (in Chinese)

National Bureau of Statistics of China (NBSC), 2004-2013. China Statistical Yearbook: 2003-2012. Beijing: China Statistics Press. (in Chinese)

Nikolic V V, Simonovic S P, Milicevic D B, 2013. Analytical support for integrated water resources management: A new method for addressing spatial and temporal variability. Water Resources Management, 27: 401-417.

Shokoohi A, Morovati R, 2015. Basinwide comparison of RDI and SPI within an IWRM framework. Water Resources Management, 29(6): 2011-2026.

Sun C Z, Zhao L S, Zou W et al., 2014. Water resource utilization efficiency and spatial spillover effects in China. Journal of Geographical Sciences, 24(5): 771-788.

Sun K K, Chen J, 2011. Evaluation index quantification for "The Three Red Lines" of water resources management in Wuhan. Journal of Yangtze River Scientific Research Institute, 28(12): 5-9. (in Chinese)

Tao J, Zuo Q T, Xue H L et al., 2012. Control indicators and determination methods of "Three Red Lines" of the strictest water resources management system. Water Saving Irrigation, (4): 64-67. (in Chinese)

The Ministry of Water Resources of China, 2004-2012. Water Resources Bulletin of China in 2003-2011. Available at: http://www.mwr.gov.cn/zwzc/hygb/szygb/. (in Chinese)

The Royal Society, 2012. Energy and water linkage: Challenge to a sustainable future. (online) https://royalsociety.org/ /media/policy/Publications/2012/energy-water/2012-05-10-g-science-energy.pdf.

Tsagarakis K P, 2013. Does Size Matter? Operating cost coverage for water utilities. Water Resour. Manage., 27: $1551-1562$.

Wang X, Li X B, Xin L J, 2014. Impact of the shrinking winter wheat sown area on agricultural water consumption in the Hebei Plain. Journal of Geographical Sciences, 24(2): 313-330. (in Chinese)

Xinhua News Agency (XNA), 2010a. The South African government will improve the quality and utilization efficiency of water resources. Website of Pearl River Water Resources Commission. Available at: http://www.pearlwater.gov.cn/gwsl/. (in Chinese)

Xinhua News Agency (XNA), 2010b. The pollution is increasingly serious in the Great Lakes of the US-Canada border. Website of Pearl River Water Resources Commission. Available at: http://www.pearlwater.gov.cn/gwsl/. (in Chinese)

Xiong H O, 2014. 172 Important hydraulic engineering projects constructed before 2020. The Beijing Business Today, 2014-05-22(2). (in Chinese)

Yang D, Zhang H, Guan X K et al., 2013. Establishment of evaluation indicator system of "Three Red Lines" for the strictest regional water resources management. Water Resources and Power, 31(12): 182-185. (in Chinese)

Yang D R, Jiang N, Ma C, 2012. Thoughts on integrated water resources management and the most stringent water resources management system. China Water Resources, (20): 13-16. (in Chinese)

Yang Y, Liu Y, 2014. Spatio-temporal analysis of urbanization and land and water resources efficiency of oasis cities in Tarim River Basin. Journal of Geographical Sciences, 24(3): 509-525. (in Chinese)

Zheng D F, Zang Z, Sun C Z, 2014. An improved ecosystem service value model and application in ecological economic evaluation. Resources Science, 36(3): 584-593. (in Chinese) 